\title{
Socio-Economic Impacts of Transit Projects (A Case Study of Orange Line Lahore)
}

\author{
Alisha Shahid ${ }^{1 *}$, Muhammad Ansub ${ }^{2}$, Asra Hafeez ${ }^{3}$, Hamza Saleem ${ }^{4}$, Aroosa basharat ${ }^{5}$ \\ ${ }^{1}$ GIS specialist, National University of Science and Technology, Islamabad, Pakistan \\ ${ }^{2}$ Town planner, University of Management and Technology, Lahore, Pakistan \\ ${ }^{3}$ Town planner, University of Management and Technology, Lahore, Pakistan \\ ${ }^{4}$ Town Planner, University of Engineering and Technology, Lahore, Pakistan \\ ${ }^{5}$ Town Planner, Lahore College for Women University, Lahore, Pakistan
}

DOI: $10.36348 /$ sjce.2020.v04i09.004

| Received: 30.10 .2020 | Accepted: 09.11.2020 | Published: 11.11.2020

*Corresponding author: Alisha Shahid

\section{Abstract}

Open spaces have significant importance in the life of the settlements. The areas with high green coverage rate have ecological and environmental importance. These green spaces can improve the urban climate, abate the urban heat- island effect by their ecological-balancer function and reduce environmental damages. In recent years, less attention has been paid to open spaces (including green areas and green spaces) and their components as well as their effect on the environment. Due to mega transit projects environment of Lahore is continuously in danger. This research have highlighted the importance of green spaces which is destroyed badly after every project. Research have also highlighted the socio economic conditions, willingness of residents of Lahore where the project of orange line was initiated. In the end of the research the authors have proposed some useful measures through which planners and engineers can hold on projects and will provide less harm to environment.

Keywords: Socio-Economic Transit Projects.

Copyright ( $) 2020$ The Author(s): This is an open-access article distributed under the terms of the Creative Commons Attribution 4.0 International License (CC BY-NC 4.0) which permits unrestricted use, distribution, and reproduction in any medium for non-commercial use provided the original author and source are credited.

\section{INTRODUCTION}

The provision of green areas inside and in the vicinity of urban areas allows us with a number of benefits and good things like these places could be used as spots of formal or informal recreation and sport activities also these could be utilized as points of relaxation and to tackle the storm water gathered in the area and also to preserve the natural environment. Now a days more emphasis is given to the provision of greener areas as the authorities or the workers are more concerned with the health of cities as well as the residents of that cities. A new, broader view of parks has also recently been emerging. The policy makers and the practitioners are more concerned with the provision of parks and open spaces in a more a valuable way that could provide the public with leisure opportunities as well as could also be used as the points that could provide job opportunities, youth development, public health and community building [1].

Now in whole of the world the cities are growing outwardly and more emphasis is regarded on the provision of greener areas that could increase aesthetics of the area, but this provision of green area in collaboration with the development at the same time in the developing nations or the countries is creating problem for them to maintain a balance between spaces, resources and development. The landscaping and the visual amenities in and around the project area any city are being harmed or affected a lot. The construction of mega projects have affected the potentials and good going of these amenities a lot. For the detailed findings of impacts of constructions projects on landscaping and open areas an ongoing project of orange line have been selected to demonstrate the before and after affects [2].

Landscaping refers to any activity that modifies the visible features of an area of land, including living elements, such as flora or fauna; or what is commonly called gardening, the art and craft of growing plants with a goal of creating a beautiful environment within the landscape. Natural elements such as landforms, terrain shape and elevation, or bodies of water; and abstract elements such as the weather and lighting conditions.

Open space in urban environment provides a number of advantages: formal and informal sports and 
recreation, preservation of and proximity to natural environments, provision of green spaces, leisure and even urban storm water management. Thus green space must be a key consideration in urban planning if the health of a city and its people both considered important. A new, broader view of parks has also recently been emerging. This new view focuses on how policymakers, practitioners, and the public can begin to think about parks as valuable contributors to larger urban policy objectives, such as job opportunities, youth development, public health, and community building [3].

Orange Line is an under-construction rapid transit line being built as part of the Lahore Metro, in Lahore, Pakistan. The Orange Line will be Pakistan's first modern rail-based mass rapid transit system and will be a fully automated and driverless system. It will be Lahore's second rapid transit line, after the Lahore Metro bus, which was completed in 2013.From Orange Line's north eastern terminus at Dera Gujjran, the track is elevated and runs in the median of the GT Road until Shalimar Station. From Dera Gujjran Station in northeast Lahore, the route travels 5.5 kilometres westward with stations at Islam Park, Salamatpura, MahmoodBooti, Pakistan Mint, and Shalimar Gardens. Leaving Lakshmi Chowk, Station is located at the intersection of The Mall and McLeod Road and approaching towards Chauburji. The line continues along Multan Road's edge until Awan Road Station, after which it reverts to Multan Road's median. Leaving Awan Road Station, the line continues to travel southwest along Multan Road until it reaches Wahadat Station, which lies $2.85 \mathrm{~km}$ to the southwest of Sabzazar Station. The line 5.2 kilometers along Multan and Raiwind Roads, with stops at Hanjarwal Station, Canal View, NiazBaig, before terminating at Ali Town.

\section{Problem statement}

As the world's cities continue to grow, continuing to value green space in cities is vital: but is also a challenge, particularly in developing nations where there is pressure for space, resources and development. Landscape and visual amenity values within and surrounding the project development area and an assessment of the potential for these values to be affected by direct and indirect impacts associated with the construction, operation and decommissioning phases of the project. For the detailed findings of impacts of constructions projects on landscaping and open areas an ongoing project of orange line have been selected to demonstrate the before and after affects [4].

Lahore was once known for its lush green gardens, but is now known for its maze of underpasses and overpasses. The surge in developmental projects, especially road widening, has taken a toll on the city's tree cover. The reduction of tree cover has removed the habitat for many species. Chopping down trees to widen roads affects both Lahore's scenic beauty, and the city's carbon sink, which is a natural or artificial reservoir that helps in removing carbon dioxide from the atmosphere. Medical practitioners have testified that an increase in the number of concrete structures leads to an increase in temperature, causing sun strokes among pedestrians and motorcyclists during the summer and other environmental issues. According to a 2007 report by World Bank, unsustainable development and the cutting down of trees-environmental degradation is costing Pakistan Rs1 billion rupees every day [5].

With Lahore's population increasing by the day, housing schemes have become a necessity. But these grand construction plans reduce the amount of land that could potentially be used for planting trees. Since there is no law which stops conversion of prime agricultural lands for housing or commercial purposes. This research work aims to preserve the City of Gardens-Lahore for making it a sustainable city. By highlighting the importance of open spaces, past and existing policies for parks will be evaluated. On the basis of that evaluation, some policy recommendations will be proposed [6].

\section{OBJECTIVES OF THE RESEARCH}

The specific research aim is further divided into following objectives

- To promote safety, pedestrian mobility, preserving of open spaces, welfare and aesthetics by highlighting the condition of Lahore before and after construction project

- To highlight the importance of parks, open spaces, green areas, for making city sustainable

- To evaluate current and past condition of Lahore due to availability of parks, open spaces and green belts.

- To draw conclusions to make reasonable measures for effective landscaping process and to recommend the different measure for preserving City of Gardens.

\section{Legislation in pakistan \\ Preservation of landscape ordinance, 1966}

In this ordinance, landscape includes earth, land, clay, rock, boulders, shingles, pebbles and any other substance over the surface of land, and grass, weeds, bushes, hedges, plants, standing trees, undergrowth and all objects of natural beauty visible to the eye.

No person shall remove, destroy damage or alter anything, or commit any other act if such removal, destruction, damage, alteration or act affects or is likely to affect a landscape injuriously.

\section{Pakistan forest policy, 1991}

Among other objectives, the policy referred to conservation of Biological Diversity and maintaining ecological balance through conservation of natural forests, reforestation and wildlife habitat improvement. 
The goals were set to increase network of Protected Areas for conservation and propagation of flora and fauna from 12 percent of the total area of the country against existing 7 percent. Local participation in the protection and conservation of resources was sought by sharing revenues from trophy hunting and promoting private game resources.

\section{Authority responsible in pakistan}

Parks and horticulture authority in the Punjab is responsible for the regulation, development and maintenance of public parks, green belts and green areas in the Punjab; regulation of billboards, sky signs and outdoor advertisements; to promote open and unrestricted views of the Punjab; and, to provide for the connected matters.

\section{Powers and functions of the authority}

The Authority shall

a) Develop and maintain public parks, green belts and green areas;

b) Regulate the use of public parks, green belts and green areas;

c) Regulate the installation of billboards, sky signs, out-door advertisements on private or public property;

d) Establish and maintain botanical gardens;

e) Organize shows and exhibitions pertaining to horticulture, aviculture and cultural entertainment; protect trees and other vegetation;

f) Create awareness about horticulture and promote gardening;

g) Acquire land for the development of any public park, green belt, or green area;

h) Procure machinery, equipment or material as may be required for the proper discharge of its functions;

i) grant a service contract for the maintenance of public parks, green belts or green areas to a company owned by it or to any other private or public limited company, constitute committees for performing specific functions of the Authority; and perform such other functions as may be ancillary, or as may be prescribed.

\section{SCOPE OF THE STUDY}

Open spaces have significant importance in the life of the settlements. The areas with high greencoverage rate have ecological and environmental importance. These green spaces can improve the urban climate, abate the urban heat- island effect by their ecological-balancer function and reduce environmental damages. Through their social importance, the open spaces can help the residents in adjust into the healthy lifestyle. By their aesthetic importance, they determine the characteristic of the settlements, ameliorating the built-up character of the cities. In order to have a thorough understanding of the problem, the project of orange line, Lahore is selected as a case study area by comparing before and after and impacts of construction projects [7].

The way to accomplish the research objectives, answering the research queries and how we perform the entire research can be termed as the research methodology. Research methodology plays vital role in answering and achieving the desired research questions. The step wise direction to complete the project within the specified time is searched out through a particular methodology adopted. Quantitative and qualitative analysis are the main parameters of the research work which includes the literature review, surveys conducted from the field and may also include the scientific approach. The desired information and data is gathered through consultation of primary and secondary sources. Different activities performed in this manner are framed out against the methods or the techniques with the prescribed time limit. The analysis is being done by using the collected data and information against different test in order to obtain the desired conclusions. In the rounds of the analysis done and comparison of information different recommendations and curative policy measure are suggested to the concerned authorities [8].

\section{SELECTION OF CASE STUDY AREA}

The green belts, spreading out in different parts of the city, are fast disappearing or being damaged, which negates the beautification of city [9]. The gradual decline in green belts in the city can be assessed by the fact that longish green belts on either side of the GT road have been encroached and occupied by cattle for last some months, resultantly that greenery is fast vanishing. Another part of the city being deprived of the green belts is the either side of the Lahore canal, and mean while Multan road where $80^{\circ e}$ green belt was ruined, one could witness heavy block of cements being prepared for the construction of orange line interchange.

These blocks have damaged the beauty of the lush green area alongside the canal. Some tress has also been chopped down to create a space for the labor activity. People residing alongside the canal showed their dismay over the process harming the green belts. The research edifies the significance of greenbelts and landscaping by proposing new design concepts for the damage. A route from Multan road to Ali town is nominated for formulating different design alternatives/solutions or a model or another visualization of roads by fulfilling the need of open spaces and overcoming the damage due to projects of road construction. 


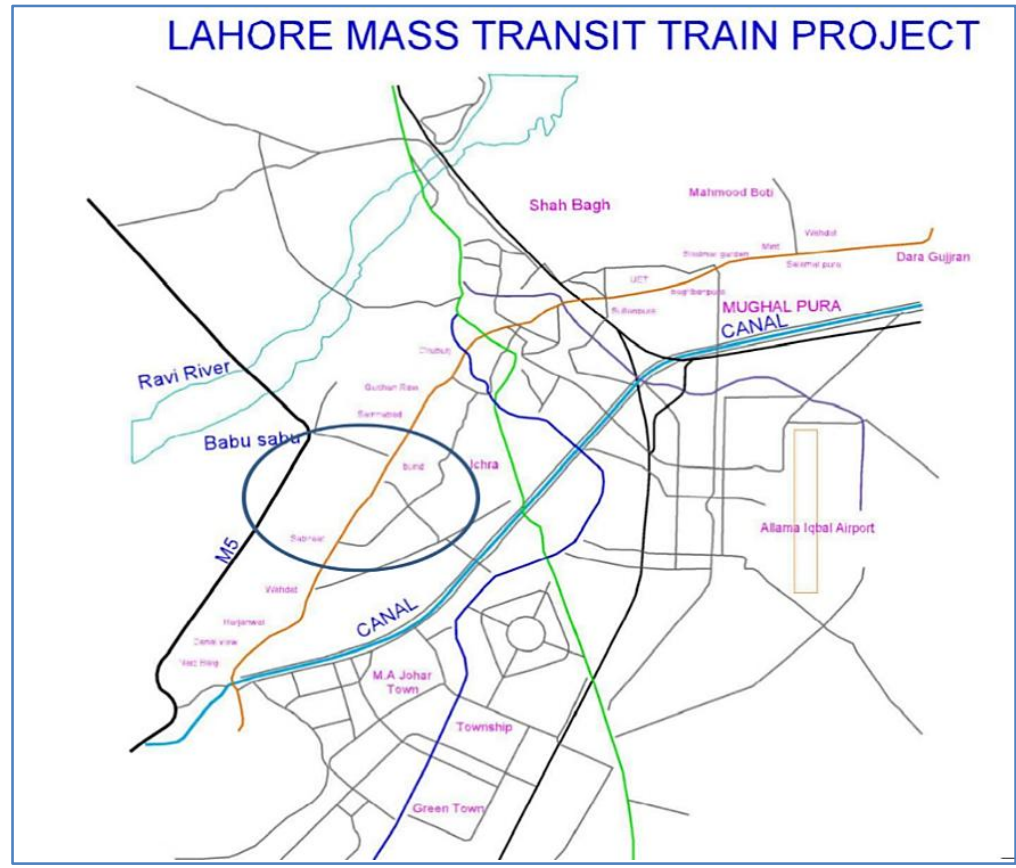

Fig-1: Source by Researchers ' 2020

\section{COLLECTION OF DATA}

The main data collection parameters are:

1. Secondary data collection through Articles, Journals and Books

2. Formal interviews from Civil engineers, Town Planners and Architects.

Table-1: Showing scheduling and work flow

\begin{tabular}{|l|l|l|}
\hline Sr. no & Surveys & Description \\
\hline $\mathbf{1}$ & Pilot / Reconnaissance survey & $\begin{array}{l}\text { To visit the whole area to demark whether this area is suitable one for } \\
\text { survey or not. To limit out a very bigger project area in the smaller } \\
\text { pocket area which can be surveyed easily and results can be drawn. }\end{array}$ \\
\hline $\mathbf{2}$ & Focus group discussion & $\begin{array}{l}\text { To conduct focus group discussion with the selected pocket area people } \\
\text { that what must be done and what must not be done in the area. }\end{array}$ \\
\hline $\mathbf{3}$ & Field survey & $\begin{array}{l}\text { Different field surveys were conducted to provide the area with } \\
\text { potentially suitable site for the provision of Greenery or green works. }\end{array}$ \\
\hline $\mathbf{4}$ & Interviews from officials & $\begin{array}{l}\text { Different interviews from officials were conducted to collect data from } \\
\text { the competent authority in our case (PHA or concerned TMA) }\end{array}$ \\
\hline
\end{tabular}

Source: developed by researchers

Table-2: Secondary data sources

\begin{tabular}{|l|l|l|c|}
\hline $\mathbf{1}$ & Satellite imagery & Google earth image & to map out the things \\
\hline $\mathbf{2}$ & Provision or rules or regulation & Competent authority & LDA, PHA and concerned TMA \\
\hline $\mathbf{3}$ & Reports/ Articles & Internet/ past practices & \\
\hline
\end{tabular}

\section{Route Map}

This the route map showing the whole of the train in a glimpse of eye. The orange line shown in the map is representing the orange line project starting from
Alipur near Raiwind and ending at the point Dera gujran near GT road. The circled area is showing the pocket of working. Which starts from Bund road and ends at Sabzazar. 


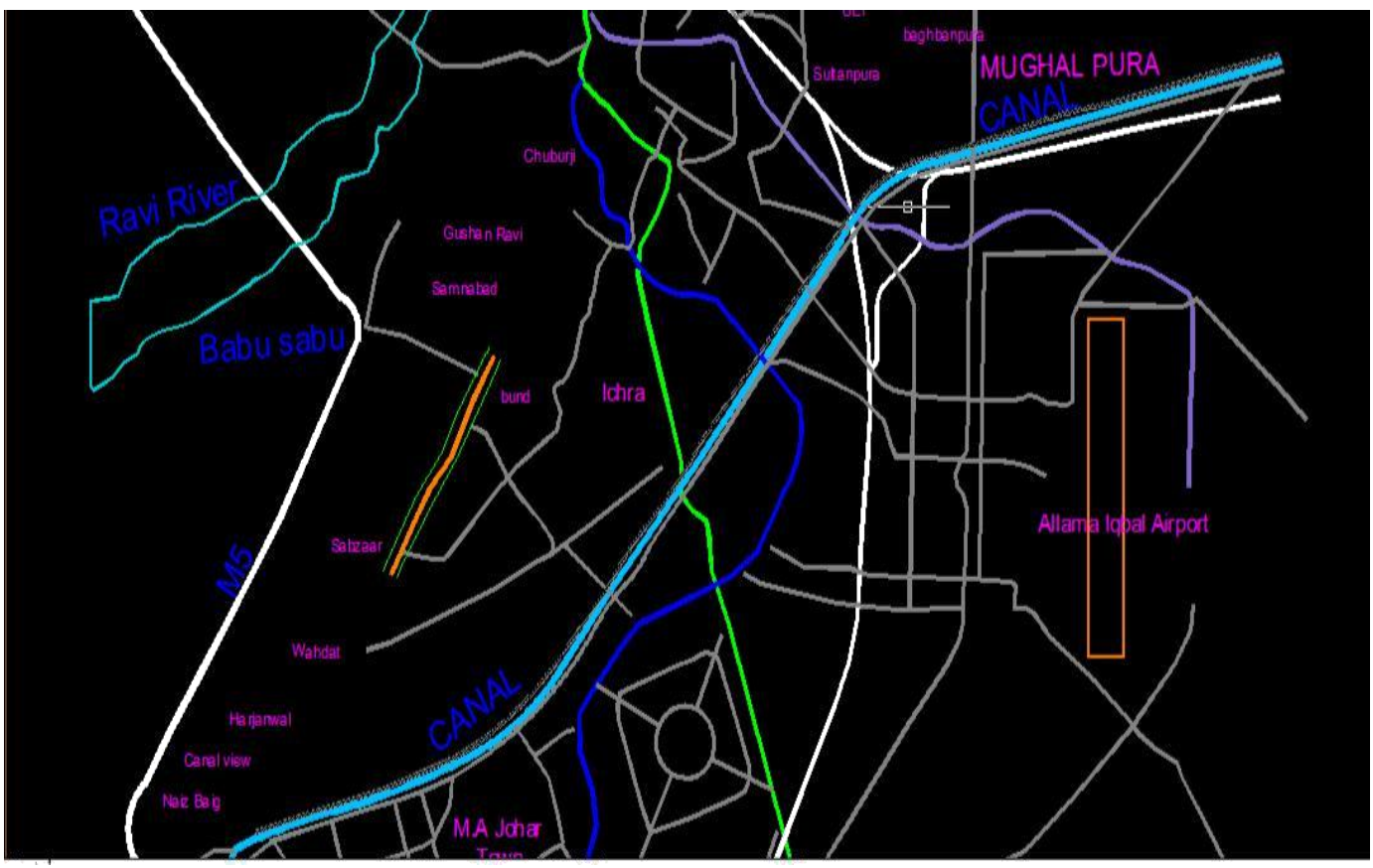

Fig-2: Pocket Area digitized

\section{Pocket area}

It was hard to do working on the whole of the orange line route or the stations, so for our further working area from the Bund road station to the Sabzazar station was selected. This makes a strip of almost $2.5 \mathrm{~km}$ in which side walkways was provided in a sense that could accumulate the persons coming to that areas. This pocket area was selected for a reason that this had an open area or the green space in the vicinity of the project area which was harmed and abolished due to the provision of the station there and also the orange line route.

\section{SOCIO-ECONOMIC SURVEY RESULTS Analysis}

The next task is to develop some analysis techniques and to analyze the proper work out and findings of the work. In this regard we use some software to facilitate our work like SPSS, Excel and word. Some tables and graphs were developed in SPSS and Excel and their write up was done Word. This is how the whole of the analysis was done, now some of the important question and observation are included in the form of charts or tables to show their outputs. The questionnaire was filled using random quota sampling and a sample size of 50 was selected to fill by the residents of the area to get the possible output.

\section{RESULTS}

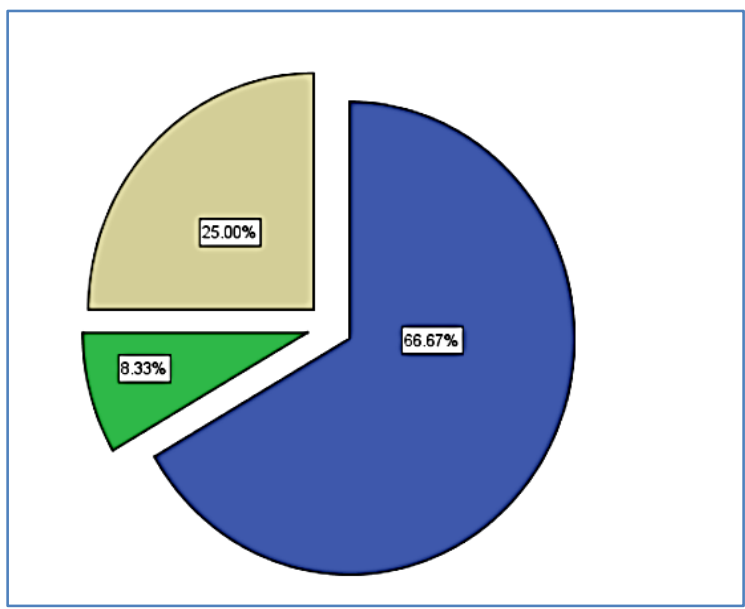

Fig-3

This is a graph showing the occupancy of the residents residing in the area that for how long they have been there in that area. The analysis shows that most of the people residing in project area are pre partition more the $60 \%$ approximately, with blue color on the figure. Similarly the grey color reflects the percentage of people residing in the area post partition and the green color shows the people after 1960s. 


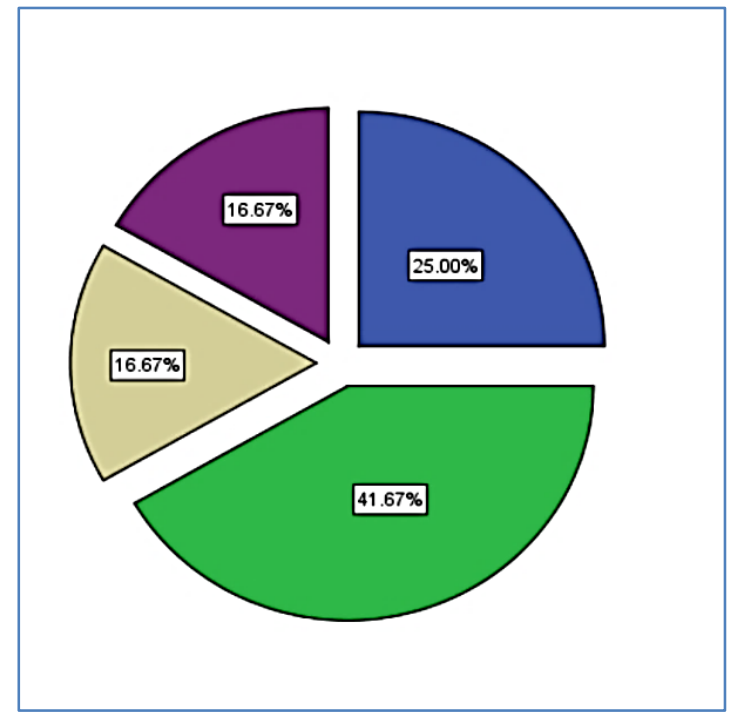

Fig-4: Road width

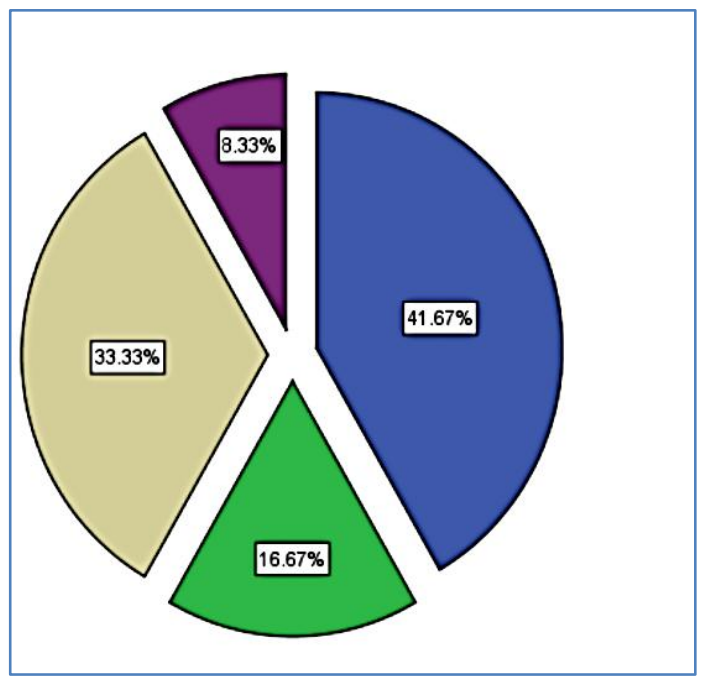

Fig-5: Occupation

This figure 4 shows the width of the roads in front of the houses. This data of right of way in front of roads would be beneficial in a sense if we could develop some green areas there and also if we want to increase the road width that how much of the area we have to take from the houses. Most of the streets in front of the houses has a right of way of $15 \mathrm{ft}$ shown with green color on the map, then blue colored portion which represents the roads having right of way of $10 \mathrm{ft}$, and similarly then $20 \mathrm{ft}$ roads and the $30 \mathrm{ft}$ roads.

The figure 5 shows the occupation of the residents of that area which was surveyed. As most of the people in that area approximately $42 \%$ are associated with the work of daily wages. Then almost $34 \%$ persons are officers or works in some kind of government offices. Then a percentage of $17 \%$ have their own business and almost $8 \%$ are doing work in some kind of organization as an employee. This would allow us to have a quick glance at the financial status of the area.

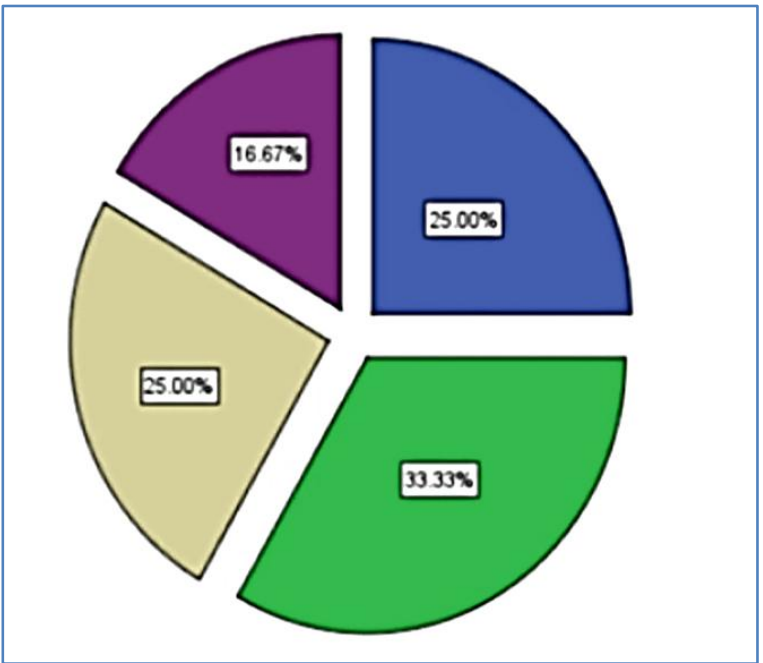

Fig-6: Troubled by orange line

Figure 6 is indicating the answers of the residents of that area whether their work is being hindered by the working of this orange line project or not. Most of the persons replied us with no because major portion of that area was daily wagers and they are now being working on the project as a labors so they got a good waging daily routine work near their residence. There were some respondents too who didn't respond to this question. Results also show that the ownership of the vehicle that the persons use for their daily commuting. As that area was a middle class area so most of the persons own bike in that area as indicated by green color. Similarly other such slices of the chart indicate the ownership of other things like cycle which is second highest in that area and then the car and other things.

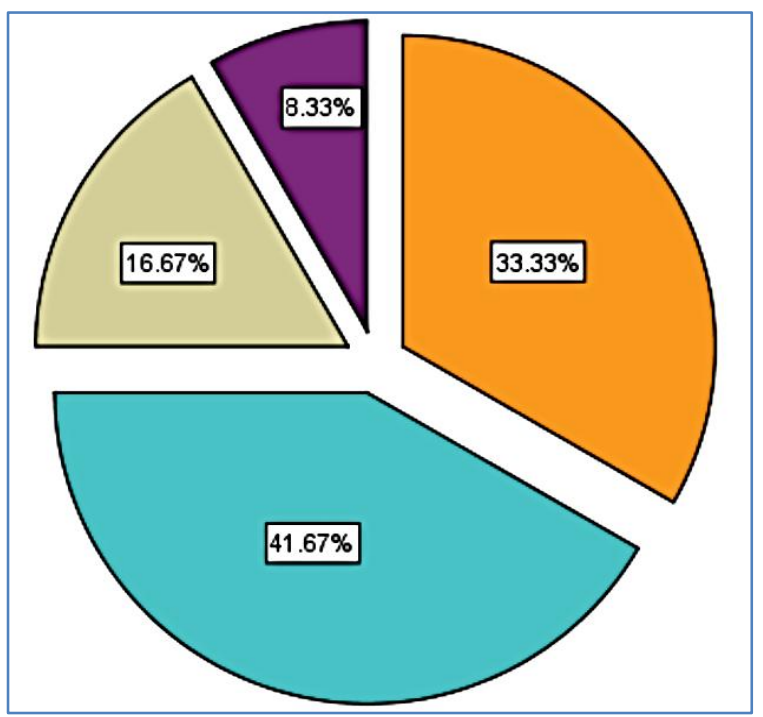

Fig-7: Use of public transport

This pie chart is related with the usage of public transport in the area. Most of the persons are using the public transport once in a week then it comes towards the $34 \%$ are using it daily and $17 \%$ in a month and $8 \%$ have hardly used this system of public 
transport. As this area is basically middle income class so most of the people uses this transport network of publically available transport that's why the slices of daily using and weekly usage of transport makes almost complete chart with almost $25 \%$ to other users.

\section{Loss of open spaces}

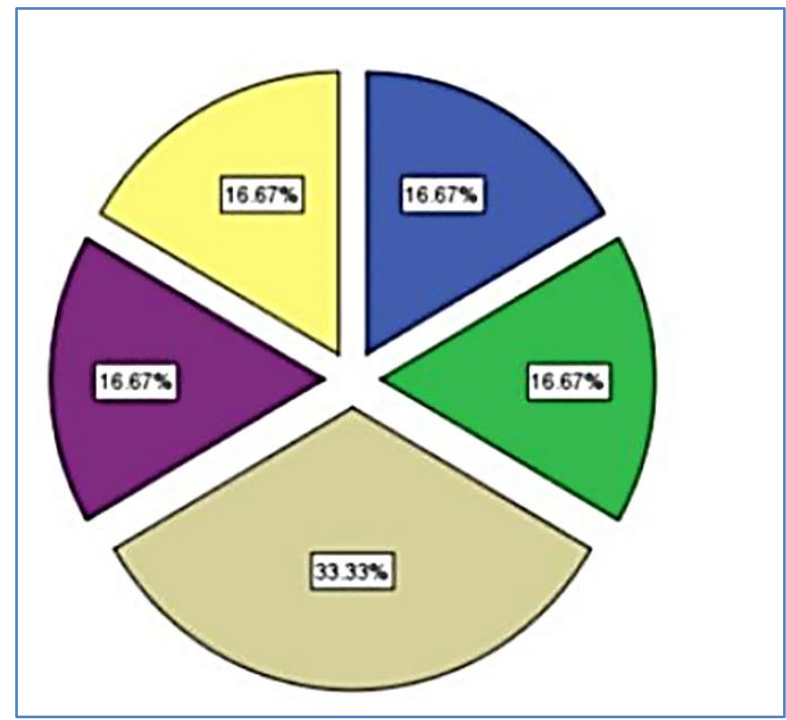

Fig-8: Problems due to orange line

This the most important question of our survey as this project of orange line is in progress for the propose of benefit and providing assistance to the public and if this public is facing some problem due to this then how would this be beneficial. In these question different problems of the area arising due to orange line is indicated. In this aspect the most important problem with consent of almost $33 \%$ people is chopping down the trees, this chopping of trees has effected the environment in a bad manner and also as we Pakistan already has very less number of trees so we must grow trees rather than chopping down the trees. The other four problems of the area has the equal proportion of difficulty which is being created due to noise pollution or raised noise in the area, also the unavailability of clean drinking water the water is contaminated with the sewage which is creating many diseases for the human like diphtheria and many others, other problems in this context of difficulty for residents of the area comes out to be open drains which are being created due to ill conditions of pathways which are running like streams, and at last another problem could be termed as heaps of garbage which are lying openly and being a cause of dust pollution and many other diseases.

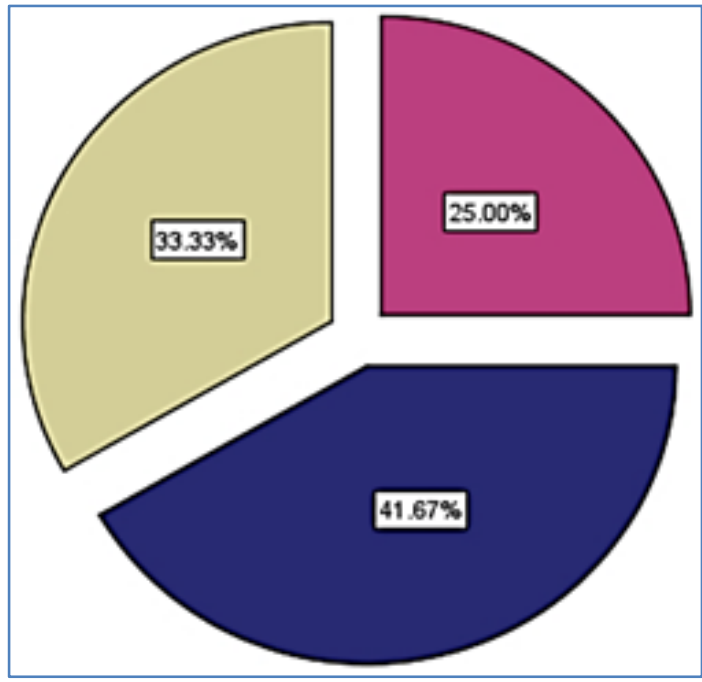

Fig-9: threats to shops

This pie chart is related with the threats that are available to the shops due to ongoing project of orange line train. As the government is going to encroach area of 30 feet in front of the buildings for the porpoise of making space for the passage of traffic and other facilities. So there is always a threat to the shops and other constructed building of being vanished from the scene or their area would be reduced down or anything else.

The description of another important aspect of our survey or the analysis as it is showing the review of the person on the question that how orange line project has affected there area, most of the people of about $34 \%$ has come up with the answer that this project has excluded all of the green spaces available in their area which has made it more cumbersome and more bad, then some people says that it has vanished the aesthetics of the area there were positive responses too that were saying the at this project has made the area of influence functionally more vibrant and good looking in its real sense.

\section{CONCLUSIONS}

After all a long and thoroughly study of landscaping and visual amenity in Pakistan specially in Lahore its concluded that in Lahore due to mega project of construction like Metro bus and orange line metro train the environment of the whole city is facing problem day by day this is all of that project which are creating so many problems because of these projects there is no concentration on environment and government of Pakistan without taking notice on bad condition of pollution day by day cutting the trees which is adversely affect the atmosphere.

If we specially see the orange line metro train that there is no proper system to increase the visual nuisance $\mathrm{f}$ city all trees around the road which are somehow good for the environment but they all are victim of this mega project. By this project government 
of Pakistan have no special system to improve the landscaping and environment quality of the city.

After a whole research we came to this point that range line metro train is crucial problem for whole city this is not just booming the problem of whole city in a way of environment it also creating the selfbusiness problem of the city, during this research and whole city we did a survey about this project about $95 \%$ people disagree with this project because their single earning business destroyed due to this project and really bad condition of whole environment.

Before these projects a city Lahore which called the city of garden but now this is called the city of concrete so this is all due to these projects which are boosting day by day without notice on the environment. In Lahore if these projects are not stooped than in future this will be really a big problem for Pakistan specially the city Lahore.

In second hand if we take this project positively and take the views of people this project will be fruitful for Pakistan specially those people which are now facing problem for this way they said that in future the value of their land and business will be very high due to this project and transpiration system is highly efficient in Lahore so whole system will be god and really admirable because this thesis on specially on orange line metro train so this way the good will be the whole city and government that before starting this project the landscaping system should be efficient all around the track of this project.

\section{RECOMMENDATION}

Before these projects Lahore is most famous city of Pakistan due to its landscaping and called the city of garden but now it's called city of concrete due to its bad condition because of large and mega projects so on discussing the topic on orange line metro train and if give a brief research on just this project that is about to complete. So before this in many places of Lahore having god atmosphere and visual amenity but after starting this project all the trees and plants around this track cut which adversely effected the atmosphere of whole city and due $t$ this in last days there was smog problem in Lahore this was really the effect of these projects, s control the same condition and same title for our main city of Pakistan government of Punjab should take step for this to give classic look to the city and maintain the same landscaping of the city before staring these projects the trees system should be increased in the whole city if we cut the tree than before cutting the tree we should grow the two trees to maintain effect which will be off course positive effect for this city in this way atmosphere will be good and the look of city will be really good and god for the health of cities living people.
Projects like metro bus and orange line metro train track should be covered with plants and trees and in coloring flowers. So around track should be grow small trees which absorb the dangerous gases which comes from smoke of the transport so this will environment will be remain suitable for whole city and condition of weather will be off course good and really enjoyable.

Our main focus is on Orange line metro train because this time this mega project is near to finished so the movement of Punjab takes step to give a attractive look to the track before its started cover the track with plants, trees and fountain, like in Multan around the track of metro bus PHA construct the greenery and fountain around the track.

Parks and Housing Authority having the main role to judge and see the whole environment of city for this this department should notice the atmosphere of that city, in this way if the city facing problem than should fill fore take notice on that, so to maintain the beauty of city around roads all tracks of major projects should be furnish with greenery which may be small plants.

To maintain the decorum of city PHA should control illegal construction on pen spaces and should be rules followed by the concerned authority and give the proper pen spaces in front on any plazas. If anyone creating problem and using open space for personal benefit he must be charged with highly fine and demolish any type of encroachment on open spaces and on road.

\section{A way forward}

The most important task for this project is to approve the project of this provision of green belts from the government. As the government only invests in the projects which are beneficial for it for this propose the idea of Pavegen tiles was introduced as it is used to convert the mechanical energy of living organism into electric energy. The major problem of Pakistan is the shutdown of Electricity or Load shedding. The benefit of using these tiles was that they convert the human Kinetic energy into Electricity. These are applied on the surfaces which are purely pedestrianized so in our context we are going to provide these pavegen tiles in the areas which we are going to provide in the form of green strips along the orange line route that could be pedestrianized easily. And all the passengers that are using orange train have to pass by this and this could turn all the kinetic energy into electrical energy. These tiles have the storing capacity in the form of batteries. This innovative idea is applied in some developed country like London, Canada and some other developed countries. So this idea is quite applicable one in our context too. 


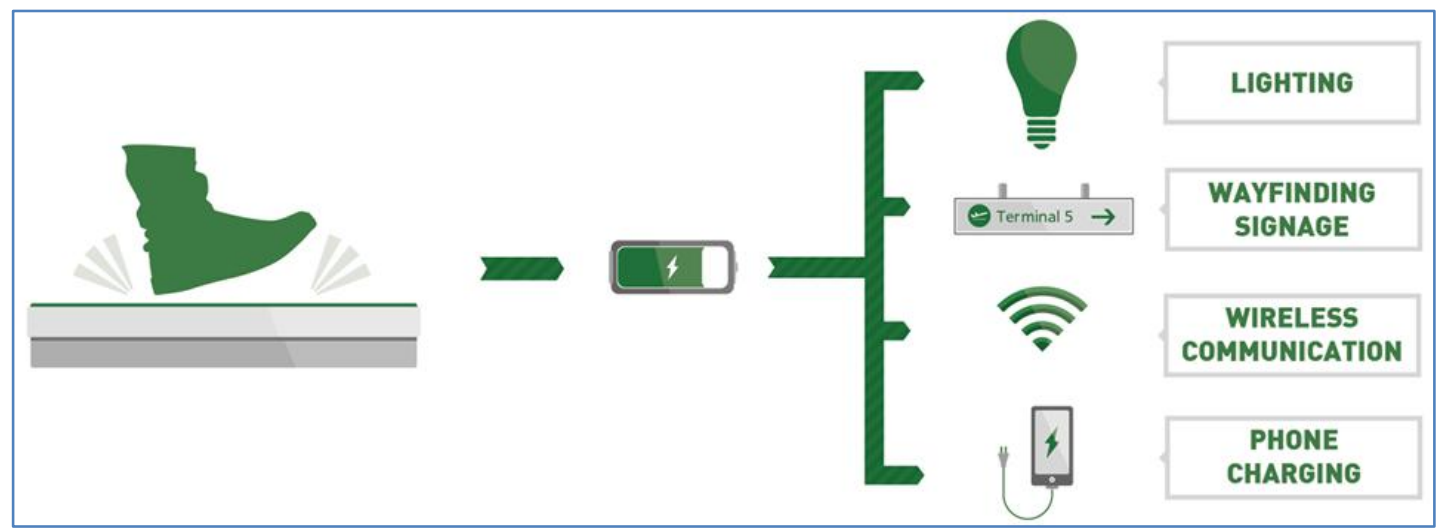

\section{Designing principles}

The design principle of pavegen is dependent upon 3 major steps

1. Data

2. Floor

3. Energy

- As the design principle is dependent upon three major steps. The first step of data deals with the collection of data.

- The data is mainly related with the identification of footsteps by their heat sensors. This data is required for the purpose of converting the footsteps in amount of energy produced.

- The next design principle is floor making.

- They makes the tiles irrigated and hard finished and durable. Just like the tiles that are used in our daily routine life. That's makes it easy to use and wash and creates aesthetics in the area.

- The last design principle is related with energy. To convert the kinetic energy into electrical energy for our daily use.

- The amount of energy produced by each foot step is almost 6 to 10 watt with a voltage of $48 \mathrm{~V}$

- It is made up of steel and recycled aluminum. And has dimensions of $500 \mathrm{~mm}$ on each edge and minimum order size of this one tile is $2 \times 4 \mathrm{~m}$, which men it has an area of approximately $8 \mathrm{~m}^{2}$.

- If we assume that we have an area of $100 \mathrm{~m}^{2}$ in which these tiles has to imposed off.

\section{REFERENCES}

1. Sajjad, F. (2014). Mega-project politics: the evolution of Lahore's first BRT corridor (Doctoral dissertation, Massachusetts Institute of Technology).
2. Rathore, K., \& Ali, K. (2015). Evaluation of Lahore Bus Rapid Transit System. International Journal of Management Sciences and Business Research, 4(10).

3. Nawaz, M., Tariq, F., Gul, A., Sheikh, N. B., \& Malik, S. (2019). Evaluation of Environmental \& Physical Impacts of Mega Transportation Projects: A Case of Lahore. Technical Journal, 24(04), 8-14.

4. Ali, S., Xu, H., Ahmed, W., Ahmad, N., \& Solangi, Y. A. (2019). Metro design and heritage sustainability: conflict analysis using attitude based on options in the graph model. Environment, Development and Sustainability, 1-22.

5. Arshad, Y. (2017). Orange line metro train project: a threat to the right to culture. Editorial Team, 4, 112.

6. Ch, M. A., Siddiqi, Z. A., \& Khan, A. M. Z. (2019). Causes of Delay in Lahore Orange Line Metro Train Project. Pakistan Journal of Engineering and Technology, 2(2), 41-48.

7. Nawaz, A., Su, X., Din, Q. M. U., Khalid, M. I., Bilal, M., \& Shah, S. A. R. (2020). Identification of the H\&S (Health and Safety Factors) Involved in Infrastructure Projects in Developing Countries-A Sequential Mixed Method Approach of OLMTProject. International journal of environmental research and public health, 17(2), 635 .

8. Malik, A. M., Rashid, M., Awan, M. Y., \& Gulzar, S. (2020). Shrines an Derelict Veracity-Case of Data Ganj Baksh: Shaikh Ali Bin Usman Al Hajveri Lahore. Pakistan Journal of Engineering and Applied Sciences, 27(2).

9. Aziz, A., Nawaz, M. S., Nadeem, M., \& Afzal, L. (2018). Examining suitability of the integrated public transport system: A case study of Lahore. Transportation Research Part a: Policy and Practice, 117, 13-25. 